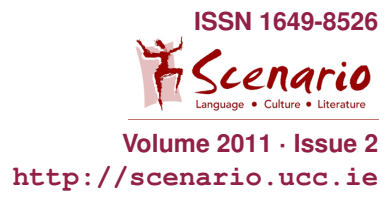

Window of Practice

\title{
Multiple Hotseating
}

\section{Susanne Even}

Most people working with drama pedagogy will be familiar with the hotseating activity: In this activity, the details of a fictional character are collaboratively constructed. One person takes the hot seat in the middle of the room as a particular character (usually from a text, but it can also be an image, a film clip, etc), and the other participants sit in a circle around this person and ask him/her questions. This is not a hidden test ("let's see how much do you remember") but serves to broaden the collective imagination. Questions asked should not be obvious but necessitate spontaneous invention. As an example: "What animal have you turned into?" seems pointless when it comes to Gregor in Kafka's The Metamorphosis, and "Lola,what color is your hair?" is equally without function after Tom Tykwer's film Lola rennt has been shown. More appropiate are open questions like "How are you feeling now, Gregor?" or "Lola, why did you fall in love with Manni?" The person on the hot seat has to answer in role, i.e. as if $s$ /he were this character, and make decisions on the spot about this very character. These decisions, in turn, are shaped by the very nature of the questions asked (for more details see Even 2008: 168f). The hotseating technique helps students get deeper into the character in question and makes the situation of this character more transparent to the others. It also encourages free interaction among the participants.

When working with student groups who are still relatively unfamiliar with drama pedagogy, hotseating might seem a daunting activity to them, and nobody wants to volunteer for the hot seat at first, except perhaps the one or two students who always raise their hands. In order to avoid this uncomfortable situation and at the same time ease more students into taking the hot seat, I started years ago with multiple hot seating. The activity remains the same, only I ask three people to take the hotseat, instead of just one. The three volunteers either sit next to each other in the front, or they sit with their backs to each other (like a three-pronged star facing outwards), with hardly any or no eye contact. They incoporate one character and they have to answer in role, as if they were that character. Whoever of the three people answers a question at a given time is up to them. This modus operandi has the following advantages: [1] A single person on the hot seat has to answer no matter what, but with multiple hotseating, students have the opportunity to remain silent. This relieves the pressure on the individual. [2] At the same time, it is a great exercise in group dynamics; students quickly develop a sensitivity for turn-taking: they hardly ever start to speak at once, and if they do, one yields the turn organically. [3] The investment in the shared imagination leads to careful listening and often 
joint embellishment of the character in question; students who are not so quick thinking on their feet can follow the lead of one of the others and develop further details.

One example: I have recently taught a course in German post-war literature. One of the texts I chose was the short story Ein Flugzeug über dem Haus by Martin Walser (first published in 1955). My students found the story extremely weird, and I couldn't much blame them. In order to approach the story from the point of multiple perspectivity, I first had the students do still images of main moments of the story. Afterwards they got together into groups and devised diary entries, summarizing the birthday party from the perspective of one of the characters: [1] a girl at the birthday party (not the birthday girl), [2] a boy at the birthday party (not the narrator), [3] the mother, and [4] the great-uncle. When done, the group members took the multiple hot seat in front of the room, read their diary entries aloud to the audience, and answered questions from the other students as if they were their character. The results were breath-taking. Often, one 'hot-seater' added a crucial detail to what another hot-seater had just said. Or one hot-seater had a challenging idea which, after the first surprised gasp, was developed further by the other hot-seaters. The students, who had never done this before, really got into this, and the safety in numbers spurned them on to truly amazing results. The relatively opaque story opened up to multiple interpretations, be it the discovery of a dysfunctional family, the narrator's possible delusions of grandeur, or the great-uncle's WWII trauma.

Walser, Martin (1997): Ein Flugzeug über dem Haus und andere Geschichten. Berlin, Suhrkamp Verlag (first published in 1955) 